\title{
Application of Diffusion Wave Method for Flood Routing in Karun River
}

\author{
Mehdi Delphi, Mohammad Mahmoodian Shooshtari, Houshang Hassoni Zadeh
}

\begin{abstract}
One of the most important subjects in river engineering is flow routing analysis of rivers which pass through important areas. Flood routing analysis includes determination of flood hydrograph and water levels at different points of flow route. Flood routing in a prismatic channel obtained with solving simultaneous continuity and momentum equation which are known as Saint - Venant equations. If inertia terms in Saint - Venant equations is removed, flow equation with complete inertia terms will be converted to diffusive equation [1]. In this study we have compared the results of full wave and diffusion wave flood routing methods in a reach of Karun river's between Mollasani and Ahvaz station. The results showed that, this methodology has a good agreement. Hence flood routing simulations using analytical, semi-analytical and numerical solution of diffusion type of Saint - Venant equations can be used in this part of Karun river.
\end{abstract}

Index Terms-Flood Routing, MIKE11, Karun river, Mollasani, Ahvaz.

\section{INTRODUCTION}

Although more hydrodynamic phenomena in rivers are Three-Dimensional physical phenomena, but when the flow followed certain path One-Dimensional flow can be considered. Mathematical models are useful tool in analysis of river flow or hydraulic structures. In this paper, according to high performance of One-Dimensional models in river studies, solve the equations governing the river flow has been considered. One-Dimensional equations governing the river flow are known as Saint-Venant equations [2]. To solve these equations depending on simplifications and desired results various methods as approximate, graphical, analytical and numerical methods are presented. Some of these methods that were used for flood routing in the past are Kinematic Wave method, Analogical diffusion method, Muskingum method presented by Cunge (Cunge, 1969) and simple methods for reservoir routing [3].

\section{FLOOD ROUTING}

Prediction the manner of flood uprising and its falling could be analyzed by flood routing. The main concept of flood routing is that if we have flow condition at upstream

M.Sc student in Civil engineering, Islamic Azad University, Shoushtar Branch, Young Researchers Club, Iran

Mohammad Mahmoodian Shooshtari, Faculty member of civil engineering, Islamic Azad University, Shoushtar Branch, Iran

Houshang Hassoni Zadeh, Faculty member of civil engineering, Islamic Azad University, Shoushtar Branch, Iran boundary, how we can determine the hydrograph at specific point of downstream boundary [4]. Obviously the hydrographs at upstream and downstream boundary will not be same. Because the path characteristics that water flows on it will change the hydrograph shape. Governing equations for gradually varied unsteady flow in open channel are given by:

$$
\begin{aligned}
& T \frac{\partial y}{\partial t}+A \frac{\partial V}{\partial x}+V \frac{\partial A}{\partial x}=o \\
& \frac{\partial V}{\partial t}+V \frac{\partial V}{\partial x}+g \frac{\partial y}{\partial x}=g\left(s_{\circ}-s_{f}\right)
\end{aligned}
$$

Equations (1) and (2) represent the continuity and Dynamic equation, respectively. These are a set of coupled non-linear partial differential equations of hyperbolic type. There are no analytical solutions for these equations, and they are usually solved by numerical methods.

\section{INITIAL AND BOUNDARY CONDITIONS}

Numerical solution of governing partial differential equations (Eqs. 1 and 2) start with calculations at a specified time. At this time, the flow conditions i.e. the flow depth, y and the flow velocity, $\mathrm{V}$ should be known. These flow conditions at the initial time are termed as the "initial conditions". Effective range of initial and boundary conditions in numerical modeling utilization showed as below [2]:

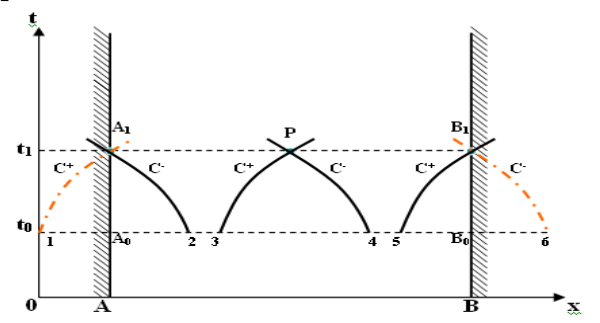

Fig.1 Initial and boundary conditions for Sub-Critical Flow

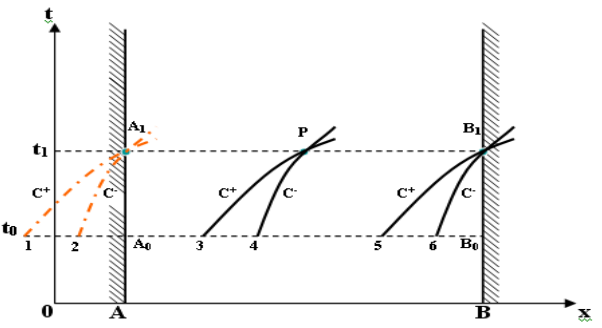

Fig.2 Initial and boundary conditions for Super-Critical Flow

In this study we had enough observed data from the flow conditions at upstream, furthermore the relationship between water level and discharge at downstream is clear. In this study we will compare the result of MIKE11 model about 
simulation of Flood routing in year 1999 with observed data [1].

\section{SOlution Scheme In Mike11}

The solution of the equations of continuity and momentum is based on an implicit finite difference scheme developed by Abbott and Ionescu (1967). The finite difference scheme used in MIKE11 (6-point Abbott scheme), allows Courant numbers up to 10-20 if the flow is clearly sub-critical (Froude number less than 1). A graphical view of this method showed as below [3]:

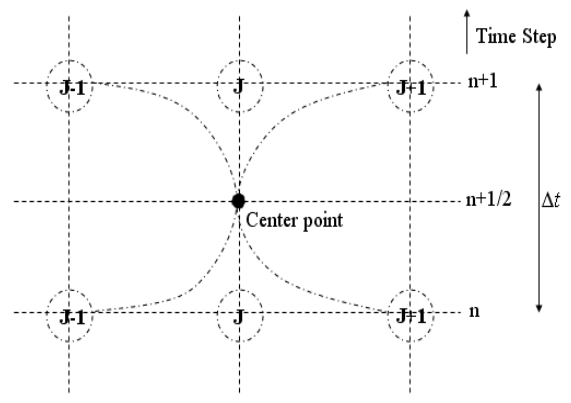

Fig.3 Centered 6-point Abbott scheme

As we can see at $n+1 / 2$ step the model bring data from steps $n$ and $n+1$, so unknowns will obtain simultaneously for each time step. MIKE11 model is fully implicit method to solve the problems and usually there is no limitation about computational steps [6].

\section{KARUN RIVER}

Karun River is only navigated River in the past that contain wide area of Iran. Its basin has been covered by provinces of Khouzestan, Lorestan, Charmahal Bakhtiari and Boyer Ahmad, respectively. Karun basin is located at middle Zagros folding and south of Karkheh river basin. Karun river length is about $890 \mathrm{KM}$ and its basin included $66930 \mathrm{Sq} . \mathrm{KM}$ and only a little part of it including plain and foothill regions. This river has a large content of permanent flow. The annual water volume of this river is more than 24 milliard cubic meters and its instantaneous average discharge value is 736 cubic meters per second in measured data. The sedimentations of this river form Khouzestan plain and expand it [1]. one useful satellite picture from the case study zone between Ahvaz and Mollasani stations that located at Karun river is taken as follow as below:

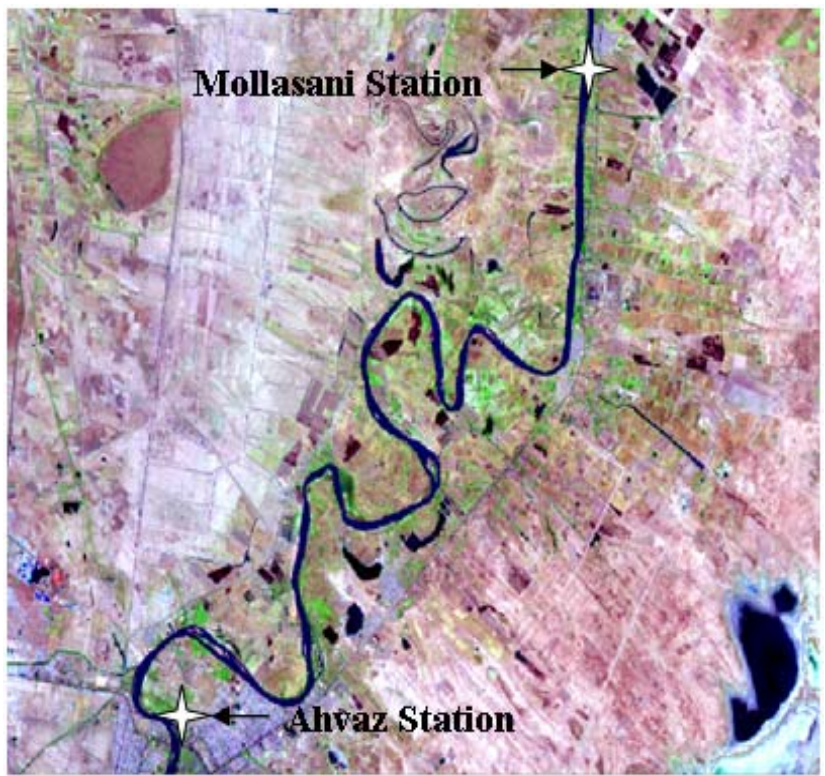

Fig.4 Satellite picture from the case study zone

\section{MODEL RuN}

After gathering the information of river network and cross sections in the reach between Mollasani and Ahvaz stations, about 61957 meter in length and 70 cross sections imported to MIKE11 software. The upstream boundary condition for Mollasani station that used in the model was flood hydrograph related to January 1999, because survey operation of cross sections is exactly done at this time, this choice will increase the accuracy of results. The downstream boundary condition for Ahvaz stations that introduced to the model is rating curve [2]. According to upstream hydrograph the model will calculate this curve at downstream. In the simulation process MIKE11 performed with approximate hydrodynamic conditions (Manning's n), after that the model calibrated by changing value of Manning's $n$ insofar as observed and measured data reached to good agreement. Thus the average resistance factor in whole of reach was obtained 0.0275 in value. Then the model performed flood routing with diffusion wave method and its results are shown as below:

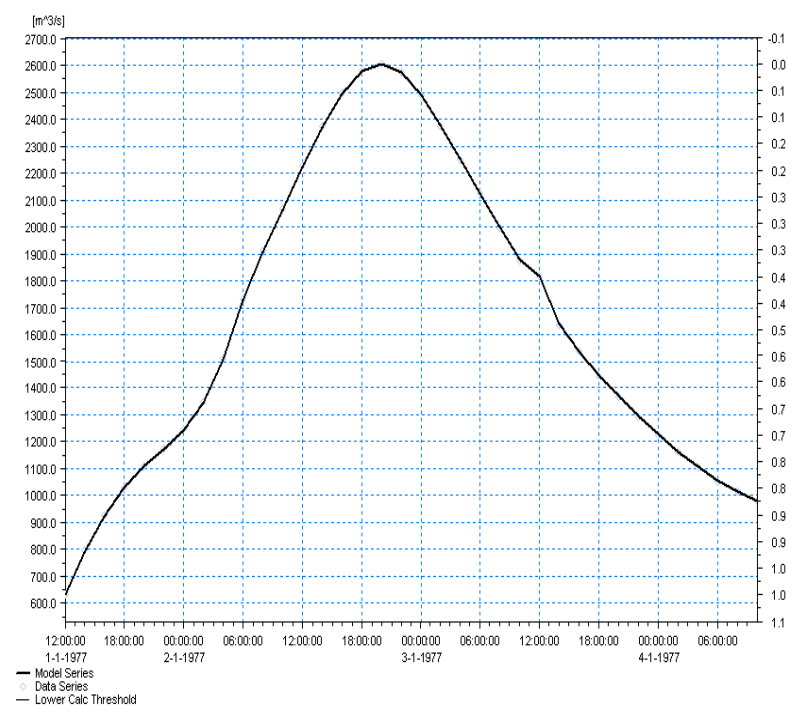

Fig.5 Observed and calculated hydrograph as Time Series

As we can see in the above picture the observed and 
calculated data has a good agreement. The statistical analysis of these data is shown as Table 1:

TABLE1. STATISTICAL ANALYSIS OF MEASURED AND MODELED DATA

\begin{tabular}{|c|c|c|}
\hline Result & Walue & \\
\hline Gorrelation coeficient R2 & ㅁ.98日 & 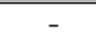 \\
\hline Max positive difference & 3.686 & $\mathrm{~mm} 3 / \mathrm{s}$ \\
\hline Wax negative difference & -5.342 & $\mathrm{~mm} 3 \mathrm{~m}_{\mathrm{s}}$ \\
\hline Volume abserved & 419652000 & $\mathrm{M}^{n} \mathrm{3}$ \\
\hline Volume modelled & 419533712.4 & Mn \\
\hline Volurne error & -0.028 & $\%$ \\
\hline Peak observed value & 2606 & $\mathrm{~m}^{n} \mathrm{O} / \mathrm{s}$ \\
\hline Peak modelled valıe & $26 \square 4.268$ & $\mathrm{~mm} 3 \mathrm{l} / \mathrm{s}$ \\
\hline Peak error & $-0.0 \mathrm{G7}$ & $\%$ \\
\hline
\end{tabular}

The error distribution of diffusion wave method of flood routing that calculated by MIKE11 is shown as below:

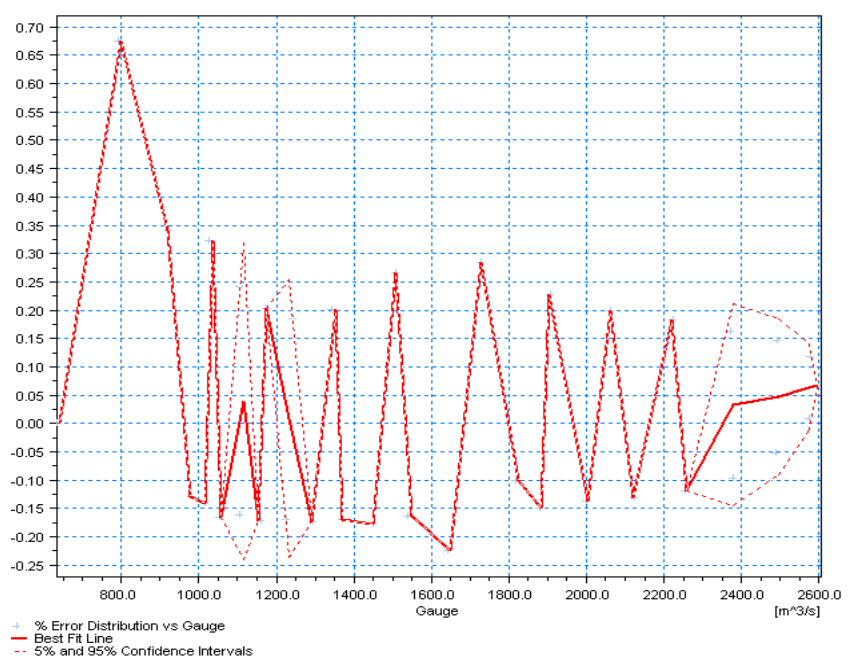

Fig.6 Best fit line in error distribution vs. gauge

\section{RESUlt AND Discussion}

AS we can see in Fig.5 and Table.1, there is a good accuracy by selecting diffusion wave method for flood routing in this reach of Karun river. Obviously the calculated error of this method in this reach is acceptable. So usage of diffusion wave method and ignoring inertia terms in Saint Venant equations at the case study zone not seem to be unreasonable approximation. Thus diffusion wave method can be used for flood routing between the reach Mollasani to Ahvaz stations of Karun river with high accuracy, and numerical solution, semi analytical and analytical schemes of this method are usable. It is tentatively suggested that the simplest and best way of solving flood propagation problems is to use the full equations with an explicit forwardstimecentred- space scheme [5].

\section{ACKNOWLEDGMENT}

I am heartily thankful to my precious professors, Gentlemen Mahmoodian Shooshtari and Hassoni Zadeh for encouragement, guidance and support from the initial to the final level enabled me to develop an understanding of the subject. Also I thank water and electricity organization in Khouzestan state for providing the data used in this study.

\section{REFERENCES}

[1] M. Delphi, Flood routing in Mollasani - Ahvaz reach of Karun River by using MIKE11 model, and comparison with Muskingum and Muskingum-counge methods, M.S. Thesis, Islamic Azad University Shoushtar Branch, 2010.

[2] M. M. Shooshtari, Principles of Flow in Open Channels, Shahid Chamran University Press, 2008, 15(2), pp 643-745.

[3] DHI Group, MIKE11 Reference Manual, 2009.

[4] Ferrick MG., Simple wave and monoclinal wave models: river flow surge applications and implications. Water Resources Research, 2005, 41(W11402): 1-19.

[5] John D. Fenton, Accuracy of Muskingum-Cunge flood routing, Institute of Hydraulic and Water Resources Engineering, 2010, 8p.

[6] Price, R. K., Volume-conservative nonlinear flood routing, Journal of Hydraulic Engineering, 2009, 135(10), pp 838-845. 